\title{
Estudo correlacional entre a Escala de Aconselhamento Profissional (EAP) e o Inventário Fatorial de Personalidade (I FP)
}

\section{Correlational study between the Professional Counseling Scale (EAP) and the Personality Factorial I nventory (IFP)}

\section{Silvia Godoy*}

Doutoranda em Distúrbios do Desenvolvimento pela Universidade Presbiteriana Mackenzie - São Paulo, SP, Brasil

\section{Ana Paula Porto Noronha**}

Docente do Programa de Pós-Graduação Stricto Sensu em Psicologia da Universidade São Francisco - USF, Itatiba, SP, Brasil

\begin{abstract}
RESUMO
O presente estudo investigou a relação entre a Escala de Aconselhamento Profissional (EAP) e o Inventário Fatorial de Personalidade (IFP), a fim de obter evidências de validade de construto convergente-divergente. A amostra se compôs de 122 estudantes do Ensino Médio de uma escola particular do interior paulista, com idade variando entre 14 e 17 anos, sendo $44,3 \%$ do sexo masculino e $55,7 \%$ do feminino. Os principais resultados apresentaram correlações significativas de 0,18 a 0,46 entre as dimensões do EAP e os fatores do IFP, a saber, Ciências Exatas com o fator Persistência, Artes e Comunicação com os fatores Instracepção e Mudança, Ciências Biológicas e da Saúde com o fator Deferência, Ciências Agrárias e Ambientais com os fatores Intracepção e Afago, Atividade Burocrática com os fatores Dominância, Exibição e Persistência, Ciências Humanas e Sociais Aplicadas com os fatores Intracepção e Mudança, e Entretenimento com os fatores Mudança, Afiliação e Assistência.
\end{abstract}

Palavras-chave: Orientação profissional, Avaliação psicológica, Interesse profissional, Testes Psicológicos.

\footnotetext{
ABSTRACT

This study researched the relationship between the Professional Counseling Scale (EAP) and the Personality Factorial Inventory (IFP) in order to validate the convergent-divergent construct. The sample considered 122 High School students from private High Schools located in the interior of São Paulo state, age between 14 and 17 years old, being $44.3 \%$ male and $55.7 \%$ female. The main results demonstrated significative correlations ranging from 0,18 to 0,46 between the EAP dimensions and the IFP factors, such as, Exact Sciences with the factor Persistence, Arts and Communication with the factor Intraceptation and Changes, Biologic and Health with factor Deference, Agrarian and Environmental Sciences with the factor Exibition and Persistence, Health and Human Sciences with the factor Intraceptation and Changes, and Entertainment with the factor Changes, Affiliation and Assistance.
} 
Keywords: Vocational Guidance, Psychological assessment, Professional interest, Psychological tests.

\section{Fundamentação Teórica}

A escolha profissional tem sido uma decisão difícil para o jovem à medida que envolve diversos aspectos relacionados à complexidade do mundo do trabalho. Sob essa perspectiva, a psicologia estruturou e vem aperfeiçoando formas específicas de ajuda, dentre as quais a orientação profissional (OP), com intuito de contribuir no que diz respeito à busca de solução dos problemas enfrentados na escolha profissional.

Pasian e Jardim-Maran (2008) destacam, dentre os objetivos da OP, o auxílio aos indivíduos com dúvidas na escolha profissional por meio de instrumentos de avaliação psicológica, estratégias relevantes para a otimização do trabalho do psicólogo. Os fatores psicológicos, familiares, educacionais, sociais, econômicos e políticos estão diretamente envolvidos no sucesso da escolha (BORDÃO-ALVEZ; MELO-SILVA, 2008). No entanto, o processo de decisão por uma atividade profissional, apesar de ser foco em muitos estudos, permanece como um desafio atual.

A ênfase no estudo do construto interesse vem ganhando destaque nos processos de orientação profissional no que refere à construção de métodos e estratégias para sua mensuração. Para Savickas (1999), o interesse é entendido como uma tendência para a satisfação de necessidades e valores pessoais, influenciando na prontidão de um indivíduo para responder a determinados estímulos ambientais. No entanto, os interesses estão associados à forma como os indivíduos procuram, no ambiente, realizar as suas necessidades e atender aos seus valores. O autor ainda compreende os interesses vocacionais como as disposições das pessoas de envolver-se em atividades profissionais que contemplem os seus valores e suas necessidades individuais.

No que se refere ao uso de instrumentos para orientação profissional, Teixeira e Lassance (2006) ressaltam a relevância da existência de modelos teóricos consistentes e de instrumentos de avaliação válidos e confiáveis que permitam investigar as variáveis envolvidas nas problemáticas vocacionais e no próprio processo de orientação. No Brasil, especialmente, ainda há a necessidade de maior incremento para mensurar interesse profissional, já que é diminuto o número de testes que possuem parecer favorável do Conselho Federal de Psicologia - CFP (2009), ou seja, uma pequena parte está em consonância com os padrões mínimos de excelência, no que se refere aos estudos das propriedades psicométricas e normatização com amostras brasileiras. 
Noronha, Freitas e Ottati (2003) corroboram tais asserções, uma vez que encontraram carência de estudos na área, destacando a necessidade do desenvolvimento de trabalhos que visem garantir a qualidade psicométrica dos instrumentos. É nesse ensejo que se insere a presente pesquisa, com vistas a relacionar a Escala de Aconselhamento Profissional (EAP) com o Inventário Fatorial de Personalidade (IFP), ambos com parecer favorável do CFP (2009). Sob esse aspecto, pretende-se contribuir com os processos de orientação profissional no que se refere à prática dos orientadores, assim como no avanço na produção do conhecimento científico.

Com relação aos estudos sobre interesse vocacional e características de personalidade, Holland, Johnston e Asama (1994) avaliaram 298 adultos que participaram de workshops sobre carreira por meio da aplicação dos instrumentos Self Directed Search (SDS) e NEO-PI que avalia os cinco traços da personalidade, a saber, Extroversão, Socialização, Neuroticismo, Realização e Abertura. Os resultados apresentaram correlações que variaram de 0,20 e 0,62, sendo que as associações significativas em ambos os sexos foram entre a dimensão Abertura e os tipos Investigativo, Artístico e Social. Adicionalmente, Neuroticismo correlacionou-se significativamente com 0 tipo Empreendedor, Extroversão com esse mesmo tipo e com o tipo Social e Realização com o tipo Empreendedor. Os autores sugeriram que esses dados reforçam a hipótese da existência de comunalidade entre os construtos interesse e personalidade.

Logue, Launsbury, Gupta e Leong (2007) investigaram a relação entre satisfação com a escolha do curso, interesses vocacionais de Holland e características de personalidade por meio da aplicação dos instrumentos Personal Style Inventory (PSI), Vocational Interests Themes (VIT) e Satisfaction with College Major em 164 estudantes universitários de um curso de Administração, sendo $42 \%$ do sexo feminino e $58 \%$ do sexo masculino, com idades variando entre 18 e 25 anos. Desses, 30\% tinham idade de 18 a 19 anos, 55\% de 20 a $21,12 \%$ de 21 a 25 e $3 \%$ mais de 25 anos. Os achados apresentaram correlação significativa entre o tipo Empreendedor e a satisfação do curso escolhido e os interesses Investigativos, Artísticos e Realísticos foram relacionados negativamente com a satisfação do curso escolhido. Nesse particular, os dados parecem indicar que, de acordo com a teoria de Holland (1997), os sujeitos do curso da área administrativa apresentam características voltadas para os negócios. No âmbito nacional, Magalhães (2006) investigou os seis tipos de personalidade vocacionais de Holland por meio da aplicação do instrumento Basic Adlerian Scales of Interpersonal Styles (BASIS-A) e do SDS. O BASIS-A é um inventário composto de 65 itens, distribuídos em 5 escalas básicas e 5 escalas suplementares, que informam sobre tendências comportamentais no contexto grupal. Participaram 393 homens e mulheres estudantes universitários, com 
média de idade 24,3 anos, que variou entre 19 e 34 , de diversos cursos, a saber, psicologia, serviço social, administração, educação física, matemática e engenharias. Os achados indicaram diferenças de estilo interpessoal entre os grupos definidos pelo tipo de personalidade vocacional. Nos tipos Artísticos, por exemplo, a média elevada na escala de 'Intitulação' do BASIS-A, na qual o sujeito acredita que deve ser o centro das atenções, podendo conseguir as coisas da sua maneira, corrobora a idéia de que estes indivíduos sentem-se merecedores do direito de divergir das convenções, optando por fazer as coisas ao seu modo e buscando a originalidade inerente à criação artística.

Por sua vez, os tipos Realistas e Investigativos mostraram escores inferiores nesta escala, confirmando as suas características de introversão e alienação social. Por outro lado, os escores elevados dos tipos Artísticos em 'Cautela', a qual avalia o quanto o indivíduo percebe o seu entorno social como hostil ou desfavorável, em comparação com Empreendedores, sugerem que a divergência e criatividade dos primeiros tende a ser manifesta na medida em que o sujeito sente-se seguro da aprovação dos demais, expondo-se somente quando está certo de que será bem recebido e/ou quando se sente preservado de críticas. Os Tipos Realistas revelaram escores inferiores na escala 'Ser Gostado' em comparação aos demais tipos vocacionais, uma vez que esta sugere a tendência para encontrar lugar no grupo conquistando a aprovação das pessoas. Este resultado, de acordo com Holland (1997, citado por MAGALHÃES 2006), é coerente com a descrição destes indivíduos como avessos à interação social, pois se percebem com poucas habilidades em relações humanas e acreditam que tarefas sociais, tais como ensinar ou cuidar, seriam frustrantes.

Ainda no que se refere às pesquisas envolvendo instrumentos de personalidade, Primi, Moggi e Casellato (2004) buscaram correlações da versão brasileira do SDS com o Inventário Fatorial de Personalidade (IFP) a partir da aplicação dos instrumentos em 81 adolescentes, sendo 78\% mulheres, a maioria com 16-17 anos que participavam de um programa de Orientação Profissional oferecido por uma universidade do interior paulista.

Os achados indicaram correlações significativas entre 0,22 e 0,39 no que se refere aos traços de personalidade do IFP com os tipos de Holland, a saber, o Realista com o traço Heterossexualidade; os tipos Social e Artístico correlacionaram-se com Assistência, Desejabilidade e com Intracepção. Por sua vez, o Empreendedor correlacionou-se com os traços Dominância, Exibição, Agressão, Autonomia, Heteressexualidade e com Ordem. Por fim, o tipo Convencional correlaciou-se com o traço Persistência. De acordo com os autores, os resultados encontrados neste estudo estão em consonância com as 
expectativas sobre as associações dos traços de personalidade com os tipos de Holland (1997) no SDS.

Mansão (2005) se propôs a validar o SDS, a partir de amostra brasileira. A autora aplicou, além deste instrumento, a Bateria de Provas de Raciocínio (BRP-5) - Forma B, o Levantamento de Interesses Profissionais (LIP) que avalia interesse pelas áreas de Ciências Físicas (CF), Ciências Biológicas (CB), Calculísticas (C), Persuasivas ( $P$ ), Administrativas (BA), Sociais (S), Lingüísticas (L) e Artística (A); e o Inventário de Interesses Angelini em 1.162 estudantes das segundas $(N=524)$ e terceiras séries $(N=638)$ do Ensino do interior de São Paulo.

No que respeita às correlações entre o SDS e as áreas de interesse profissional do LIP, verificou-se correlações significativas entre o tipo Realista e as áreas de interesse das Ciências Físicas (CF) e do Cálculo (C); o tipo Investigativo (I) associou-se com as áreas das Ciências Biológicas (CB) e CF; o tipo Artístico (A) correlacionou-se com as áreas Artístico (A), Lingüistico (L) e Social (S); O Social (S), por sua vez, apresentou correlações significativas com as áreas de interesse Social (S), relacionada a profissões que se caracterizam por atividades de contato com pessoas, essencialmente da área das ciências humanas. Ainda nessa direção, as áreas Burocrática Administrativa (BA) e Persuasiva ( $P$ ) apresentaram os maiores índices de correlação com o tipo Empreendedor, e por fim, o tipo Convencional (C) correlacionou-se com as áreas Burocrática Administrativa e Cálculo.

Em acréscimo, Sartori (2007) avaliou o perfil de preferências profissionais de 131 estudantes de Ensino Médio, de escolas particulares, com idade variando de 15 e 19 anos, média 15,90, sendo $50 \%$ do sexo feminino. A autora utilizou para avaliar os interesses profissionais a Escala de Aconselhamento Profissional (EAP) e o SDS. Os resultados apresentaram correlações significativas entre Ciências Exatas e os tipos Realista, Investigativo e Convencional. A dimensão Artes e Comunicação correlacionou-se com os tipos Artístico, Social e Empreendedor e a dimensão Ciências Biológicas e da Saúde com os tipos Investigativo e Social.

Associações significativas foram encontradas também entre a dimensão Ciências Agrárias e Ambientais e os tipos Investigativo e Social, assim como entre a dimensão Atividades Burocráticas e os tipos Convencional, Realista e Empreendedor. Por fim, a dimensão Ciências Humanas e Sociais Aplicadas apresentou correlações com os tipos Investigativo, Artístico, Social e Empreendedor e a dimensão Entretenimento com os tipos Artístico, Social e Empreendedor. A autora afirma que o EAP apresentou condições de avaliar as preferências profissionais por meio das correlações significativas apresentadas com o SDS, demonstrando ser um instrumento importante para utilização em processos de Orientação Profissional. 
Com vistas a buscar evidências de validade convergente e discriminante para a Bateria Fatorial de Personalidade (BFP), Nunes, Hutz e Nunes (2008) aplicaram o EAP e a BFP em 211 adolescentes do Ensino Médio de uma escolar particular do Estado do Paraná. As idades variam entre 16 e 18 anos e 58,3\% eram do sexo feminino. Os resultados apresentaram correlações significativas entre o fator Abertura e as dimensões Artes e Comunicação e Ciências Humanas e Sociais Aplicadas. O fator Extroversão correlacionou-se com as dimensões Artes e Comunicação, Ciências Biológicas e da Saúde, Ciências Humanas e Sociais e Entretenimento.

Por sua vez, o fator Socialização apresentou associação significativa com cinco das sete dimensões da EAP, com exceção das Ciências Exatas e Entretenimento e o fator Realização associou-se com a dimensão Ciências Biológicas e da Saúde, representada por atividades que envolvem a ajuda e cuidado de outros, além do gosto pela pesquisa. Por fim, o fator Neuroticismo correlacionou-se negativamente apenas com a dimensão Atividades Burocráticas, não apresentando correlações com as demais áreas de interesse, o que demonstra uma relativa independência entre esses domínios. De acordo com os autores, tais resultados parecem apontar a favor das considerações de Ackerman e Beier (2003), que sugerem a existência de comunalidade entre interesses e personalidade.

O estudo de Godoy, Noronha, Ottati e Dias (2008) buscou investigar a relação entre os construtos interesse profissional e personalidade. As autoras aplicaram o ECAP (Escala de Características de Atividades Profissionais), desenvolvido por Noronha, Santos e Sisto (2008), composta por 35 características de ambientes profissionais, que descrevem peculiaridades das atividades e o IFP em 122 estudantes do Ensino Médio de uma escola particular do interior paulista. A idade dos sujeitos variou entre 14 e 17 anos, com média 15,79 ( $D P=8,55)$, sendo $44,3 \%$ do sexo masculino e $55,7 \%$ do feminino.

Os achados indicaram correlações significativas entre 0 fator Assistência e os itens 'companheiros de trabalho', 'ambiente descontraído' e 'tarefas novas' da ECAP; entre o fator Afiliação e os itens 'atender público', 'ambientes abertos e descontraído', 'ter companheiros de trabalho' e expressar-se verbalmente. Por sua vez, o fator Intracepção apresentou associações significativas com os itens 'trabalho de maneira criativa' 'expressão verbal' e 'ambiente descontraído'; o fator Deferência com os itens 'ambiente descontraído' e 'tarefas novas'; o fator Dominância com os itens 'comandar uma equipe' e 'domínio de outra língua'; o fator Exibição associou-se também com o item 'comandar uma equipe'.

Ainda no mesmo estudo, o fator Desempenho apresentou correlações significativas com os itens 'liderar uma equipe' e 'domínio de outra língua'; o fator Ordem com os itens 'trabalhar em silêncio' e em 'lugares fechados', 'liderar uma equipe', 'trabalhar com tarefas 
detalhistas'; o fator Persistência com os itens 'estudo constante', 'desenvolver e executar projetos' e 'expressão verbal'. Por fim, o fator Autonomia associou-se significativamente com os itens 'liderar uma equipe', 'escolher seus horários', 'executar projetos', 'utilizar força física' e 'domínio de outra língua' e o fator Mudança com os itens 'ambientes abertos', 'expressão verbal', 'ambiente descontraído' e 'viajar'. Em síntese, por meio dos dados obtidos, as autoras ressaltam a importância da relação entre os construtos interesse profissional e personalidade.

\section{Método}

Participantes

A pesquisa contou com a participação de 122 estudantes do Ensino Médio de uma escola particular do interior paulista, sendo $44,3 \%$ do sexo masculino e $55,7 \%$ do sexo feminino. As idades dos sujeitos variaram entre 14 e 17 anos, com média 15,79 ( $D P=8,55)$. No que se refere à distribuição de séries, $27,9 \%$ dos jovens freqüentavam a primeira, $27,9 \%$ freqüentavam a segunda e $44,2 \%$ eram alunos da terceira. A primeira série é composta, em sua maioria, por alunos de 15 anos de idade $(76,5 \%)$, assim como a segunda $(52,9 \%)$ e a terceira, por alunos de 17 anos de idade $(51,9 \%)$.

Instrumentos

Foram utilizados para a coleta de dados a Escala de Aconselhamento Profissional (EAP) e Inventário Fatorial de Personalidade (IFP).

O EAP foi desenvolvido por Noronha, Sisto e Santos (2007) com objetivo de avaliar a caracterização das preferências dos participantes por atividades profissionais. A escala é composta de 61 itens, com formato Likert e as respostas devem variar de frequentemente (5) a nunca (1), de acordo com o interesse do avaliando em desenvolver cada atividade.

No que refere aos estudos psicométricos, destaca-se o estudo de validade de construto que, por meio da análise fatorial, chegou a uma solução composta por sete fatores, a saber: ciências exatas, artes e comunicação, ciências biológicas e da saúde, ciências agrárias e ambientais, atividades burocráticas, ciências humanas e sociais aplicadas, entretenimento, com índices de saturação superiores a 0,30 e variância explicada de 57,31\% .

A precisão do instrumento foi verificada por meio da consistência interna, a qual avalia a uniformidade do instrumento com relação aos seus itens. Dentre as formas para analisar a consistência interna, tratando-se da Teoria Clássica dos Testes, escolheu-se o coeficiente alfa de Cronbach e a correlação de duas metades, cujos valores de alfa ficaram entre 0,79 e 0,94 e os de Spearman-Brown e Guttman entre 0,75-0,91, considerando-se assim que as diversas dimensões do instrumento são precisas. 
O IFP é um inventário de traços de personalidade fundamentado no Edwards Personal Preference Schedule (EPPS) desenvolvido por Pasquali, Azevedo e Ghesti em 1997. Avalia no total 15 fatores, em 155 itens, sendo 135 itens referentes aos traços de personalidade, além das duas escalas que avaliam a desejabilidade social e a validade das respostas dos sujeitos ao instrumento. A escala é tipo Likert, composta de 7 pontos que correspondem progressivamente de ' 1 = Nada característico' até ' $7=$ Totalmente característico'.

No que se refere aos estudos psicométricos, com o objetivo de se aferir a validade de construto, realizou-se análise fatorial confirmatória, dentre os 15 fatores propostos pela teoria do teste, 11 explicaram cerca de $40 \%$ da variância de seus respectivos itens. Estes fatores apresentaram, em sua maioria, carga fatorial igual ou superior a 0,30. Destes, 6 possuíam uma consistência interna entre 0,78 a 0,84 e o restante com os mesmos índices superiores a $0,75,0$ que justificou a validade do instrumento.

Procedimento

Esse estudo foi inicialmente submetido e aprovado pelo Comitê de Ética em Pesquisa de uma instituição de ensino superior, e mediante a assinatura do Termo de Consentimento Livre e Esclarecido pelos respectivos responsáveis, os participantes responderam aos testes coletivamente em sala de aula, em uma única sessão, em horário previamente agendado com a instituição. O tempo de aplicação foi de aproximadamente 1 hora e as turmas foram divididas em 10 ano, 20 ano e 30 ano. Aplicou-se primeiro o EAP e em seguida o IFP. Vale ressaltar que todos os cuidados éticos exigidos na realização de pesquisas com seres humanos foram considerados.

\section{Resultados e Discussão}

A Tabela 1 apresenta a estatística descritiva do EAP. Em razão do número variado de itens que cada dimensão apresenta, é possível verificar diferentes valores máximos de pontuação. Com vistas a comparar os resultados entre os próprios sujeitos, fez-se uso do percentil, não sendo necessário, no entanto, utilizar os dados interpretativos oferecidos pelos respectivos manuais dos dois instrumentos. 
Tabela 1. Estatística descritiva das Dimensões do EAP $(N=122)$

\begin{tabular}{lrrrrr}
\hline Dimensões do EAP & Mínimo & Máximo & Média & DP & Percentil \\
\hline Ciências Exatas & 14 & 63 & 33,11 & 12,678 & 55 \\
Artes e Comunicação & 14 & 65 & 35,18 & 12,160 & 50 \\
Ciências Biológicas e da Saúde & 8 & 45 & 19,98 & 8,397 & 50 \\
Ciências Agrárias e Ambientais & 13 & 65 & 33,10 & 11,186 & 50 a 55 \\
Atividades Burocráticas & 14 & 57 & 34,05 & 9,947 & 50 a 55 \\
Ciências Humanas e Sociais Aplicadas & 10 & 45 & 23,30 & 7,040 & 45 a 50 \\
Entretenimento & 6 & 30 & 15,47 & 7,020 & 55 a 60 \\
\hline
\end{tabular}

Os maiores percentis foram encontrados nas dimensões Entretenimento e Ciências Exatas, seguidas por Atividades Burocráticas e Ciências Agrárias e Ambientais, nesta ordem respectivamente. Em outra medida, a dimensão que apresentou menor percentil foi Ciências Humanas e Sociais Aplicadas. Caracterizando os participantes em relação aos interesses, os achados indicaram que essa amostra possui preferências diversificadas, as quais envolvem atividades voltadas às relações interpessoais, ao bem-estar por meio do lazer e da diversão, à análise e interpretação de dados numéricos e às atividades organizadas que permitam o uso de sistemas informatizados.

A Tabela 2 apresenta a estatística descritiva dos quinze fatores do IFP. De acordo com Pasquali, Azevedo e Ghesti (1997), protocolos com escore acima de 30 na Escala de Validade e escore acima de 70 na Escala Desejabilidade Social não devem ser considerados válidos, uma vez que o sujeito pode ter respondido sem a devida seriedade, indicando manipulação das respostas. Vale ressaltar, no entanto, que as respostas dos estudantes nas duas escalas foram analisadas e nenhum protocolo precisou ser excluído, uma vez que a média da amostra na Escala de Validade foi 16,25 e na Escala Desejabilidade Social foi 51,27 . 
Tabela 2. Estatística descritiva dos Fatores do IFP $(N=122)$

\begin{tabular}{lrrrrr}
\hline Fatores do IFP & Mínimo & Máximo & Média & DP & Percentil \\
\hline Assistência & 21 & 63 & 47,02 & 8,360 & 45 \\
Intracepção & 20 & 63 & 43,77 & 9,716 & 45 \\
Afago & 14 & 63 & 42,05 & 9,749 & 45 \\
Deferência & 21 & 63 & 44,72 & 8,121 & 45 \\
Afiliação & 20 & 63 & 53,39 & 8,015 & 40 \\
Dominância & 14 & 63 & 38,31 & 9,720 & 50 \\
Denegação & 14 & 54 & 35,75 & 7,854 & 50 \\
Desempenho & 29 & 63 & 52,23 & 6,670 & 40 \\
Exibição & 12 & 63 & 41,89 & 9,609 & 50 \\
Agressão & 15 & 61 & 37,81 & 10,123 & 50 \\
Ordem & 12 & 63 & 44,88 & 9,812 & 45 \\
Persistência & 23 & 63 & 44,38 & 8,521 & 45 \\
Mudança & 17 & 63 & 46,97 & 9,328 & 45 \\
Autonomia & 34 & 63 & 47,89 & 6,738 & 45 \\
Heterossexualidade & 25 & 63 & 46,23 & 8,423 & 45 \\
\hline
\end{tabular}

Os maiores percentis do IFP foram encontradas nos fatores Dominância, Denegação, Exibição e Agressão. Por outro lado, os fatores, Afiliação e Desempenho foram os menos freqüentes, conforme observado na Tabela 2. No que tange às características de personalidade da amostra, os resultados indicaram que os indivíduos investigados tendem a expressar o desejo de controlar, persuadir ou comandar, impressionar, ser ouvido e visto, além de tendências a brigar, atacar e ridicularizar as pessoas.

Com vistas a atender o objetivo desse estudo, foi realizada uma análise de correlação de Pearson para verificar possíveis associações entre as dimensões do EAP e os fatores do IFP. Essas análises comparativas entre os dois instrumentos se justificam à medida que, no contexto da orientação profissional, os construtos encontram-se associados, conforme pesquisas já descritas.

A Tabela 3 apresenta as correlações entre os dois instrumentos e os respectivos níveis de significância. Verificaram-se correlações para as sete dimensões do EAP com os fatores do IFP, sendo que as mais significativas serão descritas a seguir. 
Tabela 3. Coeficientes de correlação de Pearson entre as dimensões do EAP e os fatores do IFP

\begin{tabular}{|c|c|c|c|c|c|c|c|c|}
\hline \multirow[b]{2}{*}{ Fatores IFP } & \multicolumn{8}{|c|}{ Dimensões EAP } \\
\hline & & $\begin{array}{l}\text { Ciências } \\
\text { Exatas }\end{array}$ & $\begin{array}{c}\text { Artes e } \\
\text { Comunicação }\end{array}$ & $\begin{array}{l}\text { Ciências } \\
\text { Biológicas } \\
\text { e Saúde }\end{array}$ & $\begin{array}{c}\text { Ciências } \\
\text { Agránias/ } \\
\text { Ambientais }\end{array}$ & $\begin{array}{l}\text { Atividade } \\
\text { Burocrática }\end{array}$ & $\begin{array}{l}\text { Ciências } \\
\text { Humanas } \\
\text { e Sociais }\end{array}$ & Entretenimento \\
\hline Assistência & $r$ & $-0,11$ & 0,18 & 0,15 & 0,15 & 0,02 & 0,09 & $0,22(*)$ \\
\hline Intracepção & $r$ & 0,03 & $0,44(* *)$ & 0,07 & $0,20\left(^{*}\right)$ & 0,13 & $0,41\left(^{* *}\right)$ & $0,32(* *)$ \\
\hline Afago & $r$ & $-0,17$ & $0,25\left(^{* *}\right)$ & 0,10 & $0,18\left(^{*}\right)$ & 0,03 & 0,14 & $0,22\left(^{*}\right)$ \\
\hline Deferência & $r$ & $-0,10$ & 0,16 & $0,26(* *)$ & 0,14 & 0,01 & $0,18\left(^{*}\right)$ & 0,14 \\
\hline Afiliação & $r$ & $-0,19\left(^{*}\right)$ & $0,21\left(^{*}\right)$ & 0,13 & 0,11 & 0,01 & 0,11 & $0,33(* *)$ \\
\hline Dominância & $r$ & $0,21\left(^{*}\right)$ & 0,13 & $-0,17$ & $-0,06$ & $0,27(* *)$ & 0,12 & 0,15 \\
\hline Denegação & $r$ & $-0,09$ & 0,13 & 0,04 & 0,06 & $-0,08$ & 0,04 & 0,15 \\
\hline Desempenho & $r$ & 0,29 (**) & $-0,07$ & $-0,05$ & $-0,01$ & $0,22(*)$ & 0,03 & $-0,00$ \\
\hline Exibição & $r$ & 0,14 & $0,26(* *)$ & $-0,13$ & $-0,13$ & $0,25(* *)$ & 0,12 & $0,21\left(^{*}\right)$ \\
\hline Agressão & $r$ & 0,12 & 0,12 & $-0,18$ & $-0,14$ & $0,24(* *)$ & $-0,02$ & 0,06 \\
\hline Ordem & $r$ & 0,01 & $-0,03$ & 0,07 & 0,16 & 0,02 & 0,07 & 0,07 \\
\hline Persistência & $r$ & $0,25(* *)$ & $-0,03$ & 0,02 & 0,07 & $0,25(* *)$ & 0,07 & 0,03 \\
\hline Mudança & $r$ & $-0,12$ & $0,35(* *)$ & 0,09 & 0,12 & 0,13 & $0,28(* *)$ & $0,46(* *)$ \\
\hline Autonomia & $r$ & 0,07 & 0,05 & $-0,12$ & $-0,11$ & 0,06 & $-0,05$ & $-0,07$ \\
\hline Heterossexualidade & $r$ & $0,18(*)$ & $-0,10$ & $-0,10$ & $-0,16$ & $0,23\left(^{*}\right)$ & 0,04 & 0,00 \\
\hline
\end{tabular}

Nota: ${ }^{*} p<0,05 ; * * p<0,01$

A dimensão Ciências Exatas apresentou associações significativas com os fatores Desempenho $(r=0,29)$ e Persistência $(r=0,25)$ do IFP. Noronha, Sisto e Santos (2007) destacam que as profissões são escolhidas em razão das preferências que as pessoas possuem por algumas características das ocupações, de tal forma que o agrupamento de várias delas configura um determinado campo de interesse. Assim, esses achados sugerem que pessoas que escolhem Ciências Exatas apresentam característica de Desempenho e Persistência, sendo que ambas expressam o desejo em realizar algo difícil.

A dimensão Artes e Comunicação apresentou correlação significativa com os fatores Intracepção $(r=0,44)$, Afago $(r=0,25)$, Exibição $(r=0,26)$ e Mudança $(r=0,35)$. Esses achados estão em consonância com os estudos de Godoy, Noronha, Ottati e Dias (2008), que ao correlacionar o IFP com o ECAP, as autoras encontraram associações significativas entre Intracepção e os itens 'trabalho de maneira criativa' 'expressão verbal' e 'ambiente descontraído'. O fator Exibição do IFP mostrou-se associado positivamente com o item 'comandar uma equipe' do ECAP, além de correlações significativas entre o fator Mudança com os itens 'ambientes abertos', 'expressão verbal', ‘ambiente descontraído' e 'viajar'. 
Tais resultados parecem encontrar respaldos também nas investigações de Primi, Moggi e Casellato (2004) e Magalhães (2006) à medida que o tipo Artístico do SDS apresentou associações significativas com o fator Intracepção do IFP e com a escala 'Intitulação' do BASIS-A. Pessoas com escores elevados em 'Intitulação' apresentam características de querer ser o centro das atenções, associando desta forma, ao fator Exibição do IFP.

Houve correlação também com o fator Afiliação $(r=0,21)$, o qual expressa o desejo de dar e receber afeto a outra pessoa, de se relacionar, confiança, boa vontade e amor. Nesse particular, os achados estão em consonância com o estudo de Mansão (2005) que ao aplicar o SDS em estudantes do Ensino Médio, o tipo Artístico obteve correlações significativas com as áreas de interesse social ligada a profissões que se caracterizam por atividades de contato com pessoas, como as áreas da Psicologia, Serviço Social, Pedagogia, Linguística, Letras, Ciências Sociais, História e Geografia.

Com relação à dimensão Ciências Biológicas e da Saúde, notou-se uma única associação significativa com o fator Deferência $(r=0,26)$ que, de acordo com Pasquali, Azevedo e Ghesti (1997), esses sujeitos mostram-se com respeito, admiração e reverência além de expressar o desejo de admiração a um superior, assim como de imitá-los e obedecê-los, características que possivelmente tendem a se relacionar com sujeitos que possuem interesses nesta dimensão.

Associações significativas foram encontradas entre a dimensão Ciências Agrárias e Ambientais e os fatores Intracepção $(r=0,20)$ e Afago $(r=0,18)$. O atual resultado diverge dos achados de Godoy e cols. (2008) uma vez que o fator Afago não apresentou associações significativas com qualquer item do ECAP. Além disso, notou-se também no estudo de Sartori (2007) que a dimensão Ciências Agrárias e Ambientais correlacionou-se com o tipo Investigativo do SDS, o qual apresenta características distintas dos fatores Intracepção e Afago.

A dimensão Atividades Burocráticas apresentou correlações significativas com os fatores Dominância $(r=0,27)$, Exibição $(r=0,25)$, Agressão $(r=0,24)$ e Persistência $(r=0,25)$. No Manual do EAP, Noronha, Sisto e Santos (2007) caracterizam essa dimensão com atividades relacionadas à participação de processos seletivos, admissão, demissão, classificação e organização documentos, coordenação de operações fiscais e financeiras de empresas, criação de programas de computadores, além de conduzir relações entre empresas e empregados, gerenciar serviços de aeroportos e cuidar de princípios e normas relativos à arrecadação de impostos, taxas e obrigações tributárias.

Nesse sentido, as associações entre os fatores Dominância, Exibição e Agressão com a dimensão Atividades Burocráticas permitem corroborar os achados de Primi, Moggi e Caselatto (2004), que ao 
correlacionar o IFP e o SDS encontraram resultados favoráveis entre o tipo Empreendedor que, segundo Holland (1997), descreve pessoas mais oralmente agressivas e suas preferências são voltadas às atividades que possam dominar, persuadir e liderar os outros, cujas características parecem congruentes com as atividades da dimensão em questão.

Vale destacar também, que a correlação entre a dimensão Atividades Burocráticas e o fator Persistência mostra-se coerente com a pesquisa de Godoy, Noronha, Ottati e Dias (2008), já que as autoras encontraram associações significativas entre o fator Persistência do IFP e os itens 'estudo constante', 'desenvolver e executar projetos' e 'expressão verbal' do ECAP, os quais apresentam similaridades com as características desta dimensão. Ainda, os resultados estão em consonância com os achados internacionais de Logue, Lounsbury, Gupta e Leong (2007), no qual os interesses de estudantes de um curso de Administração associaram-se com o tipo Empreendedor, reforçando as asserções dos autores supracitados.

No que se refere à dimensão Ciências Humanas e Sociais Aplicadas, associações significativas foram encontradas com os fatores Intracepção $(r=0,41)$ e Mudança $(r=0,28)$. A título de ilustração, "recuperar objetos de arte", "escrever e revisar textos", "estudar origem da evolução do homem e da cultura", "estudar o passado humano em seus múltiplos aspectos", "analisar a sociedade em questões éticas, políticas e epistemológicas" representam as atividades dessa dimensão (NORONHA; SISTO; SANTOS, 2007). O fator Intracepção, de acordo com Pasquali, Azevedo e Ghesti (1997), indica um sujeito dominado pela fantasia e imaginação, por ser pouco prático, por ser artístico e religioso, de pensar filosófico penetrante; o fator Mudança é caracterizado por não apresentar interesse por tudo que é rotineiro, preferindo as novidades, as aventuras, mudança de hábitos, lugares e comidas.

De posse dessas informações foi possível obter dados semelhantes no estudo de Nunes, Hutz e Nunes (2008) que ao investigar as correlações entre o EAP e BFP, encontrou associações significativas entre a dimensão Ciências Humanas e Sociais Aplicadas e o fator Abertura, o qual refere-se a sujeitos que reconhecem a importância de ter novas experiências, cujas características são semelhantes ao fator Mudança do IFP. Embora os instrumentos usados no presente estudo não sejam os mesmos que os usados no estudo dos autores, como eles pretendiam avaliar os mesmos construtos pode-se tentar traçar semelhanças e diferenças entre os achados. Dados semelhantes foram encontrados na investigação internacional de Holland, Johnston e Asama (1994) no qual os autores obtiveram relação significativa entre o tipo Social do SDS e o fator de personalidade Abertura. 
Por fim, a dimensão Entretenimento, ainda representada na Tabela 3, correlacionou-se significativamente com os fatores Intracepção $(r=0,32)$, Afiliação $(r=0,33)$ e Mudança $(r=0,46)$. Os resultados parecem similares com os dados encontrados nos estudos de Godoy e cols. (2008) no que se refere às associações entre os fatores Intracepção, Afiliação e Mudança do IFP com os itens 'ambientes abertos e descontraídos', 'expressão verbal', 'trabalho de maneira criativa' e 'viajar' do ECAP, os quais coincidem com as características de interesses na dimensão supracitada.

Notaram-se correlações significativas também com os fatores Assistência $(r=0,22)$, Afago $(r=0,22)$ e Exibição $(r=0,21)$. O Entretenimento, de acordo com Noronha, Sisto e Santos (2007), é caracterizado pelas atividades de produzir desfiles, catálogos, editoriais de moda e campanhas publicitárias, assim como gerenciar os serviços de aeroportos; atender hóspedes, associados e turistas em hotéis; promover a instalação de hotéis; coordenar a preparação de refeições em hotéis e restaurantes; gerenciar flats, pousadas, hotéis e parques temáticos. Sob esse aspecto, é possível inferir que as associações entre esta dimensão e os fatores do IFP estão parcialmente em concordância, à medida que os resultados mostramse semelhantes com os achados de Primi, Moggi e Casellato (2004) no que diz respeito à relação entre o fator Assistência e os tipos Social e Artístico, cujas características são voltadas para assistência, emoção e relações interpessoais (HOLLAND, 1997).

\section{Considerações Finais}

A escolha profissional tem se tornado cada vez mais importante na vida das pessoas e das organizações, à medida que o mundo do trabalho e da formação profissional está em constante transformação, assim como os indivíduos e suas necessidades de orientação. Quanto maior a relação das características pessoais com as profissionais, maior satisfação para as pessoas e conseqüentemente, melhor produtividade para as empresas.

Nesse sentido, uma intervenção adequada e eficiente do processo de Orientação Profissional, além de ser uma oportunidade para a reflexão sobre características pessoais e profissionais, pode ser um meio para a realização pessoal no que se refere à satisfação do indivíduo no ambiente em que trabalha. Desta forma, esse estudo adquire relevo no contexto nacional uma vez que envolveu a análise das relações entre uma escala que focou a caracterização das preferências por atividades profissionais, com jovens de Ensino Médio, e um inventário que avalia determinadas características da personalidade.

A relação entre os interesses profissionais e as características de personalidade foi investigada por meio da correlação de Pearson. Mais especificamente, as sete dimensões do EAP apresentaram 
correlações significativas de 0,18 a 0,46 com os fatores do IFP. Esses dados reforçam a existência de comunalidade entre os construtos, de acordo com as asserções de Ackerman e Beier (2003). Essa investigação, além de permitir uma reflexão sobre as características pessoais e profissionais, apontou que a falta de congruência entre a personalidade e o ambiente de trabalho tende a levar à insatisfação profissional, demonstrando a importância psicológica e sociológica que as ocupações refletem na vida do indivíduo.

Vale ressaltar que, mesmo tendo sido encontradas correlações significativas entre o EAP e o IFP, novos estudos deverão ser realizados, a fim de se avaliar de maneira mais abrangente questões relacionadas ao processo de escolha, especialmente no que se refere à relação entre interesse e personalidade, além de outros construtos não menos relevantes. De um modo geral, os dados observados nessa análise são considerados favoráveis no sentido de permitir a identificação de aspectos concorrentes em ambos os instrumentos. Esse tipo de estudo tende a reforçar a confiança dos processos de orientação profissional e a facilitar, em um futuro próximo, a análise dos dados dos diversos instrumentos de avaliação utilizados para tal fim.

\section{Referências Bibliográficas}

ACKERMAN, P. L.; BEIER, M. E. Intelligence, personality and interests in the Career Choice Process. Journal of Career Assessment, v. 11, n. 2, p. 205-218, 2003.

BORDÃO-ALVES, D. P.; MELO-SILVA, L. L. Maturidade ou imaturidade na escolha da carreira: uma abordagem psicodinâmica. Avaliação Psicológica v. 7, n. 1, p. 23-34, 2008.

BRASIL, Conselho Federal de Psicologia - CFP. SATEPSI - Lista de testes aprovados, 2009. Disponível em http://www.pol.org.br. Acesso em: 09/01/2009.

GODOY, S.; NORONHA, A. P. P.; OTTATI, F.; DIAS, A. S. Interesses profissionais e características de personalidade de estudantes de ensino médio. In: NORONHA, A. P.; MACHADO, C.; ALMEIDA, L.; GONÇALVES, M.; MARTINS, S.; RAMALHO, V. (Eds.). Actas da XI II Conferência Internacional - Avaliação psicológica: formas e contextos. Braga: Psiquilíbrios, 2008.

HOLLAND, J. L. Making vocational choices: A theory of vocational personalities and work environments (2 ${ }^{\underline{a}}$ ed.). Odessa, FL: Psychological Assessment Resources, 1997.

HOLLAND, J. L.; JOHNSTON, J. A.; ASAMA, N. F. More evidence for the relationship between Holland's personality types and personality variables. J ournal of Career Assessment, v. 2, n. 4, p. 331-340, 1994.

LOGUE, C. T.; LOUNSBURY, J. W.; GUPTA, A.; LEONG, F. T. L. Vocational interest themes and personality traits in relation to college 
major satisfaction of business students. Journal of Career Development, v. 33, n. 3, p. 269-295, 2007.

MAGALHÃES, M. O. Relação entre personalidades vocacionais e estilos interpessoais. Revista Brasileira de Orientação Profissional, v. 7, n. 1, p. 11-22, 2006.

MANSÃO, C. S. M. Interesses profissionais: validação do SelfDirected Search Career Explorer- SDS. 155f. Tese de Doutorado, Pontifícia Universidade Católica de Campinas, São Paulo, 2005.

NORONHA A. P. P.; FREITAS, F. A.; OTTATI, F. Análise de Instrumentos de Avaliação de Interesses Profissionais. Psicologia: Teoria e Pesquisa, v. 19, n. 3, p. 287-291, 2003.

NORONHA, A. P. P.; SISTO, F. F.; SANTOS, A. A. A. Escala de Aconselhamento Profissional - EAP Manual de Aplicação. São Paulo: Vetor Editora Psico-Pedagógica Ltda, 2007.

NORONHA, A. P. P.; SANTOS, A. A. A. SISTO, F. F. Escala de Características de Atividades Profissionais: construção e validação. Relatório Técnico, não-publicado, 2008.

NUNES, C. H. S. S.; HUTZ, C. S.; NUNES, M. F. O. Bateria Fatorial de Personalidade - BFP Manual Técnico. São Paulo: Casa do Psicólogo, 2008.

PASIAN, S. R.; J ARDIM-MARAN, M. L. C. Padrões normativos do BBT$\mathrm{Br}$ em adolescentes: uma verificação da atualidade das normas disponíveis. Revista Brasileira de Orientação Profissional v. 9, n. 1, p. 61-74, 2008.

PASQUALI, L.; AZEVEDO, M. M.; GHESTI, I. I nventário Fatorial de Personalidade - IFP Manual Técnico de Aplicação. São Paulo: Casa do Psicólogo,1997.

PRIMI, R.; MOGGI, M. A.; CASELLATO, E. O. Estudo correlacional do Inventário de Busca Auto Dirigida (Self-Directed Search) com o IFP. Psicologia Escolar Educacional, v. 8, n. 1, p. 47-54, 2004.

SARTORI, F. A. Estudo correlacional entre a Escala de Aconselhamento Profissional (EAP) e o Self-Directed Search Career Explorer (SDS). Dissertação de Mestrado, 84f., Programa de Pós-Graduação Stricto Sensu em Psicologia, Universidade São Francisco, Itatiba, 2007.

SAVICKAS, M. L. The psychology of interests. In: SAVICKAS, M. L.; SPOKANE, A. R. (Eds.). Vocational interests. Meanings, measurement and counseling use. (p. 19-56). Palo Alto, CA: DaviesBlack, 1999.

TEIXEIRA, M. A. P.; LASSANCE, M. C. P. Para refletir sobre a avaliação psicológica na orientação profissional. Revista Brasileira de Orientação Profissional, v. 7, n. 2, p. 115-117, 2006. 


\section{Endereço para correspondência}

Silvia Godoy

Universidade Presbiteriana Mackenzie, Rua da Consolação, 930, Prédio 38, CEP 01302-907, São Paulo- SP, Brasil -

Endereço eletrônico: silviagodoy04@yahoo.com.br

Ana Paula Porto Noronha

Universidade São Francisco, Rua Alexandre Rodrigues Barbosa, 45, Centro, CEP 13251-900, Itatiba - SP, Brasil

Endereço eletrônico: ana.noronha@saofrancisco.edu.br

Recebido em: 13/11/2009

Aceito para publicação em: 15/05/2010

Acompanhamento do processo editorial: Ana Maria Lopez de Calvo Feijoo

\section{Notas}

* Psicóloga e Mestre em Psicologia pela Universidade São Francisco - Itatiba, SP; Bolsista Mérito MackPesquisa.

**Doutora em Psicologia, Profissão e Ciência, pela Pontifícia Universidade Católica de Campinas; Bolsista Produtividade em Pesquisa do CNPq. 